\title{
The Nature of the Judicial Public Opinion
}

\author{
Shun ZHANG \\ Law School, China University of Political Science and Law, Beijing 100088
}

through multiple forms was greatly emphasized.

\begin{abstract}
In recent years, trial by public opinion has become a basic rule of China's judicial system in judging cases, but also one of the directions of the judicial reform. In the academic circles, two contradictory viewpoints have been formed about the trial by public opinions, but its legitimacy and rationality are over-emphasized while the deconstruction of judicial public opinion "itself" is ignored. What is judicial public opinion? How is it formed? If judicial public opinion is put in the analysis framework of syllogism, the major premise (judgment basis), minor premise (case facts) and reasoning in the forming process of judicial public opinion can be simply explained, from which the nature of judicial public opinion is demonstrated.
\end{abstract}

Keywords: Public Opinion; Media; Information Transmission; Judgment Basis; Formation Mechanism

\section{INTRODUCTION}

In recent years, the judicial organs make every effort to build an image of the administration of justice for the people, in order to keep consistent with the political idea of "ruling for the people". For this reason, they are committed to the reform of "active judiciary" and judicial democratization. In 2009, the Supreme People's Court excessively issued the Suggestions about Further Strengthening the Public Opinion Communication and the Notice about Strengthening the Public Opinion Communication through the Network, in which enhancement to public opinion communication
In a sense, there is nothing wrong with strengthening the communication between judiciary and public opinion, but some courts push the relationship between them to the acme, namely, advocate trial should consider public opinion (trial by public opinion). In a period, trial by public opinion has become a basic rule of China's judicial system in judging cases. However, whether trial by public opinion owns a legitimacy basis should be calmly thought. Professor GU Peidong thinks that trial by public opinion is of legitimacy, but the reason is that public sentence is not derogatory to judicial independence and public trial can become an important reference for judicial organs to handle cases. Professor ZHOU Yongkun thinks that public opinion involving the cases should not become a basis for trial based on three reasons: (1) the nature and characteristics of the public opinion involving the cases decided it should not be as the judgment basis; (2) trial by public opinion is against the rule of law principle; (3) trial by public opinion violates the current laws. In this paper, whether trial by public opinion is right or wrong and how to position "public opinion" will be discussed, namely, what is public opinion and what is judicial public opinion?

\section{The judicial public opinion information transmission mechanism}

Media, seen by people as a social role in mastering and performing the "fourth power", plays a strong social function. In reality, the news media is an aggregate with the characteristics of 
industries, public service, and political organization (see Fig.1). For the media, the boundaries among the three roles are not clear.

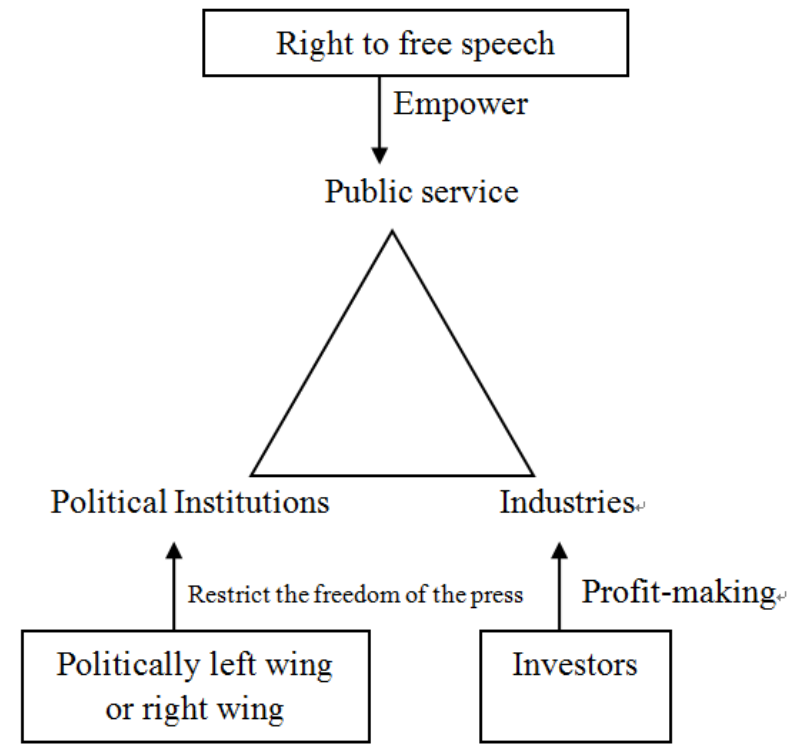

Fig. 1 the three roles of media

From the perspective of informatics, the media industry controls the right to transmit information. For the society as a whole, that a single organization or individual is responsible for the acquisition and transmission of information is in line with the principle of efficiency, but the "deterioration" of the media industry is often caused by the limitation of the state power on the media plus the profit-making requirements of investors for media.

If the state power gets involved in the game between the media and the public, the strengths of the two sides will be imbalanced. In addition to the restrictions by the state power, media will be affected by the "profit-making" expectations of investors.

On this basis, media has to report some socially sensitive but politically unimportant cases for the purpose of attracting more attention and gain a foothold in the fierce competition, as the advancement of marketization goes on. In China's process to promote the rule of law, typical and complex legal disputes often become the objects that will be captured by media. The attention from the public to cases may drive an equitable settlement to cases to a certain extent, but a more serious problem - the fairness of punishment will be generated if public opinions selectively pay attention to some focused cases.

Media tends to reshape cases while catering to the demand of the public. The expression to the case facts will be relevantly adjusted in accordance with the needs of the public, in which the social background of the parties, the social relations between the parties (e.g. bequeathing case in Luzhou), and the damage suffered by the parties in cases are deliberately stressed. In the reports of media, the case facts and the victims are often constructed.

Media controls not only the public right to access to information, but also the channels of institutions such as "government and judicial institutions" to transfer "public opinion". Whether media will transfer the information to the judicial organs according to the facts is a question difficult to make sure. First, this is because the judicial opinion tends to be diversified and does not keep the same from the beginning to the end in the perception of a case, and the opinions of the pros and cons will exist simultaneously. In reality, however, the judicial opinion expressed by media is only a type of voice. That is, judicial public opinion may have been replaced in the transferring process. Second, people are hard to effectively supervise the transmission behavior of media.

\section{The judgement base for judicial public opinion}

Seen from the requirements of the judicial syllogism, the people need to obtain the relevant legal knowledge in addition to the case information and then can judge a case. However, an important presupposition of the modern countries under the rule of law provides that ordinary people do not have legal capacity. Then, what is the theoretical foundation for the people to judge a case? That is to say, what is the people's "major premise"? What factors will 
affect the judgment of people on a case? They are divided by French scholar Le Bon into two aspects: (1) indirect factors, mainly including race, tradition, time, political and social system, education and so on; (2) direct factors, mainly including phenomenon, words and rhetoric, illusion, experience and rationality, etc. The above factors are relatively broad, which are thought to mainly focus on two aspects (common sense and reason) in this paper.

The empirical paths are often followed in common sense. In general, common sense includes two aspects: (1) the facts almost known by all people and the simple knowledge about the basic facts; (2) the truths contained in the basic facts.

The second basis of the people to make judgement is "reason", namely, the morality commonly discussed by people. Usually, the cases involving the moral field are the most easily controlled by the people's "sympathy" and "anger". Additionally, judicial public opinion is easily affected by the following factors. The first is the "victim's situation", which means that the people often set themselves to be the "victim" in the process of considering a case and view a problem from the angle of the victim. The second is external shock. Public opinion will greatly change when significant social events emerge.

\section{The forming mechanism of judicial public opinion}

In terms of decision science, judicial public opinion is a decision-making process. In general, there are four kinds of decision forms: individual decision, group decision, collective decision, and the decision affecting collective decision.

The formation of judicial public opinion is affected by group polarization. The polarization, in simple terms, means that the people with the same viewpoints develop in more and more extreme direction. This kind of phenomenon has been obvious when a jury is trying a case about "punitive damages".
A concept associated with group polarization is "waterfall effect", proposed by Sunstein, constitutional scholar of the United States. The so-called cascade effect means that public opinion is often influenced by other people within the same group, and the final result is that they will go with the flow if their ideas are inconsistent with others'. The main difference between "waterfall effect" and "group polarization" is that the second is with the nature of negotiation, but the two sides are also affected by two mechanisms: (1) information mechanism; (2) reputation mechanism.

Group polarization and waterfall effect should be more significantly demonstrated in the forming process of judicial public opinion. In many focused cases, public opinions are often not uniform at the beginning and the people often view cases differently, but their opinions seem to tend to be consistent as time delays. Do public opinions really come to an agreement? The two main reasons are analyzed in this paper. First, "silence spiral" plays a role. That is, the people will more boldly release and diffuse their own opinion if they see the viewpoints they agree with are popular widely among the masses, but will keep silent if a viewpoint is acclaimed by a few people. The silence of one party will give rise to the increasing influence of the other party's opinion, thus promoting a spiral development process to emerge. Second, a result of unreasonable abuses exists. Many people will hold an extreme attitude toward others whose opinions are inconsistent and push the personal attacks fully to the society.

\section{Conclusions}

Through the above analysis, the forming process of judicial public opinion has begun to unfold. From the angle of syllogism, public information about cases is restricted by the media information ability, but the bases of the public to judge cases are common sense, reason, and other factors, but not law. The range of common sense is limited by individual experience, while reason is vulnerable 
to be operated by mood, sympathy, etc. In the deductive process of major premise and minor premise, the public does not possess reasoning ability and are often affected by group polarization and waterfall effect. As shown in Fig.2, the above is a rational analysis in this paper, and the plot of "the doctrine" is very serious for ordinary people. The plot of "the doctrine" refers Case information: media control to only caring about the results, but mentioning no legal bases and evidences for case trial. Many people indulge in the plot: the most important is that any criminal that the public feel very greatly angry about shall be sentenced to criminal punishment, but what he commits as well as the evidences ignored.

+ Judgment bases: common sense, reason, etc.

Decision $\begin{gathered}\text { Group polarization and waterfall effect } \\ \text { Judial public opinion }\end{gathered}$

Fig.2 The judicial public opinion under syllogism

\section{References}

[1] Beidong GU. Analysis and Interpretation on Public Opinion in Judgement $[\mathrm{J}]$. The Jurisprudence of China, 2008 (04).

[2] Yongkun ZHOU. Public Opinion Trial and Judicial Rules [J]. Legal Science Monthly, 2009, (8).
[3] [France] Remy - Eiffel. What Is Media? -New Practice, New Traits, and New Influence $[\mathrm{J}]$. Translated by Changyi LIU. The Publishing House of Communication University of China, 2009, page: 128-129.

[4] [France] Claude, Jean-Bertrand. The Code of Professional Ethics and Responsibility System for Media [J]. Translated by Jianxin SONG, Zhenqi LIU. The Commercial Press, 2006 , 